\title{
Role of Coronary Microvascular Dysfunction in Takotsubo Cardiomyopathy
}

\author{
Cristiana Vitale, MD, PhD; Giuseppe MC Rosano, MD, PhD; Juan Carlos Kaski, DSc, MD, DM (Hons)
}

\begin{abstract}
Takotsubo cardiomyopathy (TTC) is a relatively frequent acute cardiac condition, but its pathogenesis has not been established as yet. Since the first descriptions of TTC, microvascular dysfunction has been advocated as a possible pathophysiological mechanism underlying the left ventricular wall motion abnormalities that characterize the syndrome. Several noninvasive and invasive methods have confirmed the involvement of coronary microvascular abnormalities in the pathogenesis of TTC, but whether microvascular dysfunction is the primary cause or a secondary phenomenon is still debated. The greater prevalence of TTC among postmenopausal women, along with the relationship identified between physical and emotional triggers and other "neuro-cardiac" mechanisms, suggest that increased microvascular reactivity, possibly sympathetically mediated, may play a pathogenic role in susceptible individuals. This review critically evaluates the possible role of microvascular dysfunction in the development of TTC. (Circ J 2016; 80: 299-305)
\end{abstract}

Key Words: Microcirculation; Takotsubo cardiomyopathy; Women

$\mathbf{T}$ akotsubo cardiomyopathy (TTC), also known as "transient left ventricular (LV) apical ballooning syndrome" or "stress-induced cardiomyopathy", is an acute clinical condition mimicking acute myocardial infarction. ${ }^{1,2}$ Initially described in 1991 by Sato et al in Japan, ${ }^{3}$ the condition has now become a relatively frequent occurrence worldwide. The typical presentation of TTC with chest pain, ischemic ECG changes and acute congestive heart failure leads to the initial diagnosis of anterior wall myocardial infarction. The typical angiographic (or echocardiographic) appearance with bulging of the LV apex ("apical ballooning") and hypercontractility of the basal segments of the LV has given TTC its name; that is, "takotsubo", the Japanese word for octopus pot. ${ }^{4}$ The LV systolic dysfunction that characterizes TTC is often associated with diagnostic ST-segment elevation in the anterior ECG leads and increased cardiac troponin levels, albeit in the absence of obstructive epicardial coronary artery disease (CAD). In most cases, the clinical onset of TTC appears to be triggered by an acute emotional and/or physical stress, albeit in many cases the iatrogenic effect of certain pharmacological agents has been identified as a trigger (Table 1). ${ }^{5,6}$ Recurrent episodes of TTC are not common, but cases have been described. ${ }^{7,8}$ The prevalence of TTC has been reported to be approximately $1-3 \%$ of all patients (up to 6-9\% if only women are considered) attending emergency units with a diagnosis of acute coronary syndrome. ${ }^{9}$ There is an increased prevalence (up to $90 \%$ in some series) of postmenopausal women, with a mean age ranging from 62 to 76 years. ${ }^{10}$ The clinical course of TTC is usually benign and it is often characterized by a rapid improvement of
LV systolic function over a period of days or few weeks. The long-term prognosis of TTC is generally favorable, even though complications (ie, acute heart, cardiogenic shock, arrhythmias etc) may occur during the acute phase of TTC in some patients. The rate of cardiovascular death ranges from $0 \%$ to $7 \% .^{10,11}$ The etiology of TTC has not been established as yet, and several and heterogeneous pathophysiologic mechanisms have been proposed to explain its occurrence, as summarized in Table 2 . The notion that coronary microvascular dysfunction may have a pathogenic role in TTC is currently gaining acceptance and this review aims to critically assess the potential role of coronary microvascular abnormalities in the pathogenesis of this intriguing syndrome.

\section{Microvascular Dysfunction in TTC}

The vast majority of patients presenting with TTC have angiographically normal coronary arteries or nonobstructive CAD ( $<75 \%$ stenosis). ${ }^{12}$ Therefore, with obstructive coronary atherosclerotic disease ruled out as a cause of TTC, the coronary microcirculation has been identified as a suitable candidate that may play a central role in the pathophysiology of the syndrome. As is known, the coronary microcirculation, involving the coronary pre-arterioles and arterioles $(<500 \mu \mathrm{m}$ in diameter), modulates coronary blood flow in response to neural, mechanical and metabolic factors and its dysfunction compromises myocardial perfusion. With the use of invasive and noninvasive methods of assessing coronary artery microvascular abnormalities, several authors have reported data that

Received December 22, 2015; accepted December 22, 2015; released online January 13, 2016

Department of Medical Sciences, IRCCS San Raffaele Pisana, Rome (C.V., G.M.C.R.), Italy; Cardiovascular and Cell Sciences Research Institute, St George's, University of London, London (G.M.C.R., J.C.K.), UK

Mailing address: Juan Carlos Kaski, Professor, DSc, MD, DM (Hons), FRCP, FESC, FACC, FAHA, Cardiovascular and Cell Sciences Research Institute, St George's, University of London, Cranmer Terrace, London, UK. E-mail: jkaski@ sgul.ac.uk

ISSN-1346-9843 doi:10.1253/circj.CJ-15-1364

All rights are reserved to the Japanese Circulation Society. For permissions, please e-mail: cj@j-circ.or.jp 
Table 1. Proposed Pathophysiologic Mechanisms of TTC

Catecholamine-induced LV myocardial dysfunction

Neurogenic stunning of the myocardium; impaired adrenergic neurotransmission

Diffuse coronary endothelial function

Multivessel epicardial coronary artery spasm

Coronary microvascular dysfunction

LV outflow tract obstruction and abnormal LV-arterial coupling

Acute atherosclerotic plaque rupture in the left anterior descending coronary artery; aborted myocardial infarction

with spontaneous coronary artery recanalization

Overstimulation of the myocardial $\beta 2$-adrenoreceptor $\mathrm{G} 1$ pathway

LV, left ventricular; TTC, Takotsubo cardiomyopathy.

\begin{tabular}{|c|c|c|}
\hline Class & Agents & Proposed mechanism \\
\hline Sympathomimetic & Dobutamine & Vasoconstriction through adrenergic overstimulation and LV midcavity obstruction \\
\hline Sympathomimetic & Ergonovine & $\begin{array}{l}\text { Vasoconstriction (vasospasm) by stimulation of } a \text {-adrenergic and serotonin recep- } \\
\text { tors and by inhibition of endothelium-derived relaxing factor release }\end{array}$ \\
\hline \multirow[t]{6}{*}{ Adrenergic } & Oxymetazoline & \multirow{2}{*}{$\begin{array}{l}\text { Vasoconstriction through stimulation of } a 2 \text {-adrenergic receptors in the central } \\
\text { nervous system when administered at low doses and achieving low blood concen- } \\
\text { trations (higher doses stimulate peripheral } a \text {-adrenoceptors) }\end{array}$} \\
\hline & & \\
\hline & Venlafaxine (V) & \multirow{2}{*}{$\begin{array}{l}\text { Catecholamine reuptake inhibition in presynaptic neuron (increased concentration } \\
\text { of epinephrine }[N, D, V] \text { and serotonin }[D, V] \text { ) }\end{array}$} \\
\hline & Epinephrine & \\
\hline & \multirow[t]{2}{*}{ Ephedrine } & $\begin{array}{l}\text { Increased sympathetic stimulation, cardiomyocyte toxicity microvascular, spasm, } \\
\text { cardiac myocyte stunning }\end{array}$ \\
\hline & & Sympathetic nervous system activation \\
\hline \multirow[t]{2}{*}{ Anticholinergic } & \multirow[t]{2}{*}{ Atropine } & Enhances the ability to displace catecholamines from storage \\
\hline & & $\begin{array}{l}\text { Sites in noradrenergic nerves, thus causing sympathetic nervous system hyperac- } \\
\text { tivity }\end{array}$ \\
\hline Antineoplastic & $\begin{array}{l}\text { 5-Fluorouracil } \\
\text { Combretastatin }\end{array}$ & $\begin{array}{l}\text { Increased sympathetic stimulation, cardiotoxicity } \\
\text { Induces cytoskeletal changes in endothelial cells, increases vascular permeability, } \\
\text { and inhibits blood flow }\end{array}$ \\
\hline $\begin{array}{l}\text { Vascular endothelial growth } \\
\text { factor receptor antagonist }\end{array}$ & Pazopanib & Inhibition of endothelial nitric oxide synthase \\
\hline Phosphodiesterase III inhibitor & Anegrelide & Coronary artery spasm \\
\hline Synthetic thyroid hormone & Levothyroxine & Mimics catecholamine-mediated stimulation of $\beta$-adrenoceptors \\
\hline
\end{tabular}

Abbreviations as in Table 1.

point towards a role for microvascular dysfunction in TTC. One of the major obstacles facing clinical research in the field is the limitation of coronary angiography to visualize blood vessels $<500 \mu \mathrm{m}$ in diameter. Surrogate techniques have therefore been used by researchers worldwide to try and overcome, at least partially, this limitation.

\section{Evidence From Semiquantitative Invasive Techniques}

Using the Thrombolysis In Myocardial Infarction (TIMI) frame-count technique, a validated index of coronary blood flow, studies have reported diffuse TIMI frame-count abnormalities that are suggestive of a generalized increase of coronary microvascular resistance in patients with TTC. ${ }^{13-19}$ In an international multicenter study, Fazio et al, ${ }^{16}$ assessing TIMI frame-count, reported the occurrence of slow coronary flow in 23 of 24 consecutive patients ( 20 women, 4 men; average age 67.4 years). The role of microvascular abnormalities was ruled out by the authors as they argued that despite the evidence of slow flow, suggestive of microvascular dysfunction, only 9 patients were shown to have a slowdown of the coronary flow in all 3 subepicardial coronary arteries. Furthermore, the akinetic LV area was considered to be larger than that supplied by dysfunctional microvessels. The conclusions in this small study were largely speculative. Recently, Khalid et al ${ }^{17}$ using a "corrected TIMI Frame-Count" (CTFC) technique, found a difference in slow-flow abnormalities in diverse coronary artery territories in 16 women (mean age $68.31 \pm 10.88$ years) with a diagnosis of TTC. They used CTFC to compensate for differences that could be derived from the length of the LAD coronary artery compared with other shorter coronary arteries. They found that CTFC in the LAD artery was statistically higher in patients with TTC compared with control subjects, although no flow differences were found between TTC patients and controls in the other vessels. The authors argued that the greater impairment of coronary blood flow in the LAD territory in TTC could explain why the apex is often severely affected in TTC, whereas the base of the heart tends to be spared. In contrast to those findings, ${ }^{17}$ Sharkey et $\mathrm{al}^{18}$ did not find significant differences in TIMI frame-count measurements in 59 TTC women compared with controls. They found that TIMI frame-count was only modestly prolonged in TTC compared with controls, with a large degree of variability, thus not supporting a pathophysiologic role for microvascular dysfunction in TTC. Another retrospective study by Elesber et al, ${ }^{19}$ using the TIMI myocardial perfusion grade (TMPG) classification scheme of coronary artery blood flow, found that at the 
time of patient hospital admission, angiographic evidence of abnormal myocardial perfusion was present in 29 of 42 (69\%) women (mean age 72 years) with TTC. Perfusion abnormalities involving multiple coronary territories were observed in $86 \%$ of the patients, together with a direct correlation between the degree of myocardial injury, as measured by both peak cardiac troponin levels and ECG abnormalities (ST-segment elevation and T-wave inversion), and the severity of microvascular dysfunction as assessed by TMPG. Coronary flow reserve $(\mathrm{CFR})$ is a measure of coronary microvascular dysfunction under stable hemodynamic conditions and in the absence of epicardial coronary artery stenosis. CFR can be measured both invasively and noninvasively, with a Doppler catheter or wire, and using contrast-enhanced transthoracic harmonic echo Doppler, respectively. Using a Doppler guidewire technique in 8 consecutive TTC patients (mean age $71 \pm 13$; 7 women), Kume et $\mathrm{al}^{20}$ observed decreased coronary flow velocity reserve in all 3 coronary arteries in the acute phase of the syndrome. The observed improvement in LV wall motion dysfunction, together with recovery of CFR, during follow-up, supported the role of coronary microvascular dysfunction as a possible pathophysiological mechanism determining the peculiar wall motion alterations of the LV in TTC. Of interest, however, in a very small (almost anecdotal) group of TTC patients, Abe et al did not detect significant abnormalities in CFR. ${ }^{21}$

\section{Evidence From Noninvasive Methods}

Doppler transthoracic echocardiography (TTE) allows noninvasive analysis of both LV wall motion and coronary flow, as well as serial evaluation of LV function and coronary flow in the setting of transient events such as TTC. In addition, repeat echocardiography is useful (and recommended) to demonstrate the recovery of LV function and microvascular dysfunction, as well as to assess the occurrence of possible complications. Using myocardial contrast echocardiography (MCE) with microbubble infusion in TTC patients, Abdelmoneim et al found significantly lower myocardial blood flow velocity and myocardial blood flow in dysfunctional LV segments compared with LV segments showing normal wall motion during the acute phase of the disease. ${ }^{22}$ These findings were suggestive of a potential pathogenic role of microvascular abnormalities and endorsed by 2 other studies as follows. Rigo et al, using echo-dipyridamole $(0.84 \mathrm{mg} / \mathrm{kg}$ over $6 \mathrm{~h})$ in 30 consecutive patients with TTC ( 5 men; age $68 \pm 12$ years), showed marked diffuse coronary microcirculatory disturbances in the acute phase (day 1), with early reversal to near-normal values within a few days (pre-discharge, day 7), paralleling the functional recovery in regional wall motion abnormalities at day 7 , which remained stable at 6-month follow-up. ${ }^{23}$ Similarly, in 15 consecutive women $(68+14$ years $)$ with TTC and in patients with anterior STEMI, Galiuto et $\mathrm{al}^{24}$ found a concordant reduction in myocardial perfusion within the dysfunctional LV area in the acute period in patients with TTC and in those with STEMI. Their study used MCE at baseline during adenosine infusion and at 1-month follow-up. Of interest, unlike STEMI patients, TTC subjects showed both a transient reduction of myocardial perfusion and a complete and spontaneous recovery of myocardial perfusion and contractility at 1-month follow-up. The correlation between microvascular perfusion and contractility changes in these studies is suggestive of a role for microvascular dysfunction in TTC. Also supportive of the pathogenic role of the coronary microcirculation in TTC are studies by Meimoun et al. ${ }^{25,26}$ In their first study, ${ }^{25}$ they used TTE-CFR assessment with adenosine in the acute phase of TTC and also at follow-up approximately 1 month later, in
12 consecutive patients ( 11 women; mean age $68+10$ years). TTE-CFR was found to have improved between examinations, but the wall motion score was reduced. As CFR and hyperemic flow velocity had improved at follow-up, whereas baseline diastolic flow velocity remained unchanged, the authors suggested that a blunted vasodilating capacity was present during the acute phase of the syndrome (rather than invoking a higher metabolic state) as a cause of the lower initial CFR. Later, the same group of investigators confirmed, in a larger study of 20 TTC patients (mean age $70 \pm 9$ years; 19 women) that the presence of a transient impairment of CFR in the acute phase of TTC was related to a reduced vasodilating capacity, attributable to systolic LV dysfunction. ${ }^{26}$ These studies suggest that the acute and transient involvement of microvascular dysfunction in patients with TTC has a central role in the pathophysiology of TTC. To the best of our knowledge, only 1 study, by Sganzerla et al in 2008 and involving just 7 patients, did not report abnormalities in CFR during the acute phase of the disease or at follow-up. ${ }^{27}$ Nuclear cardiac imaging [ie, single-photon emission CT (SPECT) and positron emission tomography (PET)] has also been used to characterize patients with TTC. PET, in particular, has provided information regarding myocardial perfusion, myocardial metabolism and local sympathetic nervous activity, thus representing a valuable tool for studying the pathogenesis of TTC. Several studies assessing coronary microvascular dysfunction using $99 \mathrm{~m}$ Tc-tetrofosmin myocardial SPECT showed a decrease in tracer uptake during the acute phase of TTC and a return to normal at follow-up, thus suggesting a pathogenic role for the coronary microcirculation as a trigger of myocardial ischemia. ${ }^{13,28-31}$ In these studies normalization of perfusion usually occurred in parallel with the recovery of LV ejection fraction over time. Useful information has been obtained from studies simultaneously evaluating myocardial perfusion, fatty acid metabolism and cardiac sympathetic function. In one such study, Kurisu et al ${ }^{15}$ carried out serial tallium-201 $\left({ }^{201} \mathrm{Tl}\right)$ studies and iodine123 - $\beta$-methyl-piodophenyl penta-decanoic acid ( ${ }^{123}$ I-BMIPP) dual-isotope myocardial SPECT in 14 women (mean age $72 \pm 9$ years) with TTC. They demonstrated that, during the acute phase, perfusion defects had a lesser magnitude when assessed by ${ }^{201} \mathrm{Tl}$ compared with ${ }^{123}$ I-BMIPP (assessment of myocardial fatty acid metabolism), but had a similar magnitude at 1-month follow-up. This finding suggests that myocardial fatty acid metabolism is more severely impaired than myocardial perfusion during the acute period, paralleling the apical akinesia. This discrepancy between myocardial perfusion and fatty acid metabolism appears to improve gradually during follow-up, even though the metabolic impairment persists beyond the resolution of the systolic dysfunction. In the same study, but when just the 28 female TTC patients were considered, Kurisu et al demonstrated severe impairment of coronary blood flow in all coronary arteries immediately after the onset of symptoms. ${ }^{15}$ Using the same tracers, but following their patients for a longer time, Sato et $\mathrm{al}^{32}$ confirmed the presence of a marked perfusion-fatty acid metabolism mismatch in the LV apex during the acute phase, which improved at 6-month follow-up in 35 consecutive TTC patients ( 8 men, 27 women; mean age, $71 \pm 13$ years). In their study, the authors also assessed coronary endothelial function using acetylcholine provocation testing and demonstrated epicardial coronary artery spasm in 8 of 35 patients $(23 \%)$ and diffuse coronary vasoconstriction in 19 of 35 patients $(54 \%)$. These 19 patients had no coronary atherosclerosis and in 13 of them acetylcholine induced diffuse coronary vasoconstriction directly correlated with typical chest pain and ST-segment depression. The results of this study 
Table 3. Study Findings Supporting Sympathetically-Mediated Coronary Microcirculatory Impairment in TTC

1. Increased plasma catecholamine concentrations associated with acute emotional and/or physical stress ${ }^{41}$

2. Elevated catecholamine levels reduce myocytes viability through cyclic adenosine myophosphate-mediated calcium overload ${ }^{42}$

3. Catecholamines are a potential source of oxygen-derived free radicals, and in animal models, cause myocyte injury ${ }^{43}$

4. Histologically, catecholamines have been associated with the development of contraction-band necrosis, a unique form of myocyte injury characterized by hypercontracted sarcomeres, dense eosinophilic transverse bands, and interstitial mononuclear inflammatory response ${ }^{41}$

5. Administration of catecholamines, such as epinephrine and dobutamine triggers TTC ${ }^{44}$

6. Extensive LV microvascular endothelial cell apoptosis observed in myocardial biopsy 45

7. Increased sympathetic tone from mental stress can cause vasoconstriction in patients without coronary artery disease ${ }^{46}$

8. Activation of sympathetic innervation to the heart results in coronary vasoconstriction, secondary to activation of $a$-adrenergic receptors ${ }^{47}$

9. Peculiar distribution of sympathetic nerves and changes in density of adrenoreceptors in the LV myocardium. Indeed, there is evidence that the apical segments of the myocardium have enhanced responsiveness to sympathetic stimulation, thus making the apex more vulnerable to sudden surges in catecholamine levels ${ }^{48,49}$

10. Raised levels of catecholamine may cause direct damage to the myocardium. Supraphysiologic activation of $\beta 1$ - and $\beta 2$-adrenoreceptor via stimulatory G-protein could result in cardiotoxic oxidative stress through cyclic adenosine monophosphate-dependent protein kinase A-mediated calcium overload of the cellular cytoplasm and mitochondria, resulting in cell death ${ }^{50}$

11. Higher frequency of leucine-type genetic polymorphism of guanine nucleotide binding GRK5 in patients with TTC. In the leucine type with a higher GRK5 activity than in the glutamine type, receptors are more likely to be uncoupled with sympathetic nerve stimulation ${ }^{51}$

12. Evidence of sympathetic nerve imaging with ${ }^{123}$ I-MIBG of cardiac sympathetic denervation in regions with wall motion abnormalities in patients with TTS ${ }^{52}$

GRK, G-protein-coupled receptor kinase. Other abbreviations as in Table 1.

agree with findings by Tsuchihashi et al, in whose study epicardial coronary spasm was provoked in 10 of 48 TTC patients $(21 \%) .{ }^{33}$ Similarly, Matsuo et al, using ${ }^{123}$ I-BMIPP SPECT showed an impaired metabolic metabolism limited to the apical region of the LV. ${ }^{34}$ Several studies, evaluating simultaneously myocardial perfusion and myocardial glucose metabolism showed that myocardial glucose metabolism is affected to a greater extent than myocardial perfusion in the LV territories with impaired contractility. ${ }^{35-38}$ This so-called "inverse perfusion-metabolism mismatch" is consistent with post-ischemic myocardial stunning caused by multivessel coronary disease or diffuse coronary microvascular abnormalities. Owa et $\mathrm{al}^{39}$ performed serial comparative metabolic, perfusion and sympathetic innervation studies with SPECT using BMIPP and ${ }^{201} \mathrm{Tl}{ }^{123} \mathrm{I}-\mathrm{MIBG}$, respectively, over a 1 -year period in 4 patients with TTC occurring after emotional stress. The authors reported mildly impaired myocardial perfusion with a more profound alteration of fatty acid metabolism in the apical myocardium, paralleling the occurrence of myocardial contraction abnormalities. The defective uptake seen with both BMIPP and ${ }^{201} \mathrm{Tl}$ improved within 3 weeks. However, MIBG imaging showed that sympathetic denervation persisted for 1 year after the acute event, which suggests that TTC may occur as a result of a persistent disturbance of cardiac sympathetic innervation. Cardiac magnetic resonance (CMR) has emerged over the past decade as an important noninvasive imaging tool for the diagnosis and follow-up of TTC patients. A large, prospective, CMR study, conducted at 7 tertiary care centers in Europe and North America and involving 239 patients with TTC provided useful functional and tissue data. ${ }^{40}$ Indeed, the authors identified a specific set of CMR diagnostic criteria in patients with TTC, characterized by a typical pattern of LV dysfunction in a noncoronary regional distribution pattern, myocardial edema developing in the same location as the regional wall motion abnormality, absence of significant late gadolinium enhancement images indicative of necrosis/fibrosis, and increased early myocardial gadolinium uptake, suggestive of inflammation. At follow-up, CMR imaging showed complete normalization of the LV ejection fraction and inflammatory markers in the absence of significant fibrosis in all patients.

\section{Clinical Observations in the Context of Clinical Research Study Results}

The aforementioned studies have demonstrated the presence of transient myocardial hypoperfusion generally colocalized with the typical LV contractile dysfunction seen in patients with TTC. Moreover, there is a coincidental improvement of both myocardial perfusion and myocardial function during followup in most patients. These findings are consistent with the hypothesis that severe, albeit reversible, coronary microvascular dysfunction may have a pathogenic role in TTC. However, whether coronary microvascular dysfunction is the primary cause of the syndrome or an associated secondary phenomenon remains to be elucidated. Based on current data, the most plausible hypothesis is that one or several mechanisms may cause the syndrome in a given individual but different causes may trigger TTC in different patients (Table 3).

\section{Catecholamine-Induced LV Dysfunction and Microvascular Dysfunction}

The hypothesis that TTC is caused by catecholamine-induced endothelial dysfunction and/or direct myocyte damage is plausible and does not exclude coronary microvascular dysfunction as a cause. Both "neurogenic LV stunning" and "catecholamine toxicity" can trigger coronary microcirculation dysfunction and impair LV contractility in predisposed subjects. ${ }^{53,54}$ The effects of catecholamine "surges" on coronary physiology and heart rhythm are well known. The Vodoo death, a term coined in 1942 by WB Cannon, refers to death from fright and the author postulated that death in these cases is caused "by a lasting and intense action of the sympathoadrenal system", a generalized autonomic "storm", occurring as a result of a life-threatening stressor and that has both sympathetic and parasympathetic effects but is mainly associated with direct cardiac catecholamine toxicity. ${ }^{55}$ The coronary microcirculation receives its innervation from neurons that originate in the brainstem and mediate vasoconstriction, which supports the concept that myocardial stunning caused by coronary microvascular dysfunction in patients with TTC may be neurogenic. Myocardial necrosis can be observed in patients with acute neurovascular events, ${ }^{56}$ and this is caused by direct 
toxicity of endogenous catecholamines released into the heart via neural connections. Catecholamines released directly into the heart via neural connections have a greater toxic effect than those that reach the heart via the bloodstream. ${ }^{57} \mathrm{~A}$ sympathetic nervous system "storm" also induces the production of adrenal catecholamines, which act directly on receptoroperated calcium channels, leading to an acute impairment of LV function and to coronary microvascular constriction. ${ }^{53,54,58}$ Diffuse coronary microvascular dysfunction and microvascular endothelial damage resulting from a surge in catecholamine secretion is mediated via $\beta-1$-adrenoceptor activation. The hypothesis of a sympathetically-mediated coronary microcirculatory impairment is supported by several human and clinical studies, as well as by the finding of regional metabolic abnormalities, as assessed by 123-MIBG-enhanced imaging during the acute phase of the disease, in association with regional perfusion defects. ${ }^{41-52}$ The finding of a discrepancy between myocardial perfusion and fatty acid metabolism also reinforces the concept of "myocardial stunning", which is supported by several studies, as mentioned previously in this review.

\section{Microcirculation Abnormalities and Sex in TTC}

As TTC typically affects postmenopausal women, a possible influence of sex hormones on both coronary vasoreactivity and endothelial function needs to be considered. Under physiologic circumstances estrogen beneficially affects the coronary microcirculation via endothelium-dependent and -independent mechanisms, improving CFR. ${ }^{59,60}$ During the menopause, however, both increased sympathetic drive and endothelial dysfunction are a consequence of reduced estrogen levels. ${ }^{59-61}$ The menopausal hot flushes typically reported by menopausal women are related to an acute derangement of sympathetic drive and circulatory functions. Increases in coronary endothelin levels have also been reported in menopausal women and this may further enhance coronary microvascular constriction. ${ }^{62}$ Indeed, many studies support the notion that an imbalance in the sex hormonal milieu may lead to vasomotor instability with a propensity towards vasoconstriction and endothelial dysfunction that can predispose postmenopausal women to microvascular dysfunction, myocardial impairment, and coronary arterial wall instability. Furthermore, changes in the sensitivity and/or density of the cardiac $\beta$-adrenergic receptors occurring after the menopause may predispose women to the development of sympathetically-mediated myocardial stunning. A large proportion of TTC cases are triggered by emotional or physical stress. Again, these are associated with enhanced sympathetic activity and may induce endothelial dysfunction. Evolutionary evidence suggests that as a result of repeated or prolonged exposure to physical stress, in men (more than in women) cardiomyocyte adrenergic receptor density can increase, which may have a protective effect against severe catecholamine surge (via a delay in the saturation of these receptors). ${ }^{13,63}$ Excessive vasoconstriction, an impairment of endothelium-dependent vasodilation and an augmented sympathetic activation in response to acute mental stress has been reported by Martin et al in women with a history of TTC, compared with age-matched postmenopausal controls and patients with myocardial infarction. ${ }^{64}$ The presence of generalized microvascular endothelial dysfunction in patients with TTC has been confirmed by Barletta et al who found that catecholaminergic hyperstimulation induced by the cold pressor test causes an abnormal response by the coronary circulation in TTC patients compared with controls (ie, no increase in coronary blood flow, and development of new LV wall motion abnormalities), similar to those commonly seen in the acute phase of the syndrome. ${ }^{65}$ Ueyama et al reported that emotional stress could induce reversible $\mathrm{LV}$ wall motion abnormality (LV apical ballooning) in the rat heart and this phenomenon was prevented by pretreatment with alpha- and $\beta$-adrenoceptor blockers. ${ }^{66}$ The same group of investigators ${ }^{67}$ also reported that in oophorectomized rats, those animals receiving estrogen supplementation had less cardiac dysfunction than those on no replacement therapy. They postulate that estrogen attenuates stress-induced hypothalamo-sympathoadrenal activation and thus the increase in heart rate and blood pressure normally triggered by emotional stress. Current evidence thus indicates that estrogen deficiency facilitates the occurrence of TTC, particularly that linked to emotional stress. Contrary to this, Brenner et al ${ }^{68}$ found higher estradiol concentrations in TTC women during the acute event compared with age-matched women with normal coronary arteries, and with women with atherosclerotic myocardial infarction. However, they did not match patients by menopausal age or body mass index, which are important determinants of postmenopausal estrogen levels. The authors speculated that TTC patients have higher estradiol levels after menopause compared with age-matched counterparts with atherosclerotic myocardial infarction, with the higher estradiol levels offering vascular atheroprotection, thus culminating in stress cardiomyopathy as opposed to atherothrombosis, which has a less favorable prognosis. The authors also suggested that an estrogen-deficient (eg, postmenopausal) state predisposes to TTC, but the subset of postmenopausal women with higher estradiol levels might have more atheroprotection, and thus are more prone to TTC. These conclusions clash with the large body of evidence that suggest high estrogen levels attenuate the adverse effects of increased sympathetic activity.

\section{Conclusions}

TTC is a complex acute clinical cardiac condition mimicking acute myocardial infarction that results from a generalized reduction of myocardial perfusion (in the absence of obstructive CAD) that in turn leads to a severe impairment of LV contractility involving areas of increased wall stress, such as the mid LV wall and the apex. The frequent association between TTC and severe emotional or physical stress supports a neurogenic origin for the disease through increased adrenergic stimulation directly or indirectly affecting cardiac perfusion and function. Increased coronary microvascular constriction has been documented in TTC patients and can play a pathogenic role. The postmenopausal female predominance among TTC patients suggests that ovarian hormone deficiency may represent an important predisposing factor contributing to the increased susceptibility of the coronary microcirculation to adrenergic stimulation and impaired coronary endothelial function that has been documented in TTC patients. Further clinical research and suitable experimental models are required to gain insight into the causes, triggers and molecular mechanisms responsible for TTC.

\section{Acknowledgments}

None.

\section{References}

1. Prasad A, Lerman A, Rihal CS. Apical ballooning syndrome (TakoTsubo or stress cardiomyopathy): A mimic of acute myocardial infarction. Am Heart J 2008; 155: 408-417.

2. Pelliccia F, Greco C, Vitale C, Rosano G, Gaudio C, Kaski JC. 
Takotsubo syndrome (stress cardiomyopathy): An intriguing clinical condition in search of its identity. Am J Med 2014; 127: 699-704.

3. Sato H, Taiteishi H, Uchida T. Takotsubo-type cardiomyopathy due to multivessel spasm. In: Kodama K, Haze K, Hon M, editors. Clinical aspect of myocardial injury: From ischemia to heart failure. Tokyo: Kagakuhyouronsha, 1990; 56.

4. Tsuchihashi K, Ueshima K, Uchida T, Oh-mura N, Kimura K, Owa $\mathrm{M}$, et al; Angina Pectoris-Myocardial Infarction Investigations in Japan. Transient left ventricular apical ballooning without coronary artery stenosis: A novel heart syndrome mimicking acute myocardial infarction. J Am Coll Cardiol 2001; 38: 11-18.

5. Amariles P. A comprehensive literature search: Drugs as possible triggers of Takotsubo cardiomyopathy. Curr Clin Pharmacol 2011; 6: $1-11$.

6. Izumi Y. Drug-induced Takotsubo cardiomyopathy. Heart Fail Clin 2013; 9: 225-231.

7. Singh K, Parsaik A, Singh B. Recurrent takotsubo cardiomyopathy: Variable pattern of ventricular involvement. Herz 2014; 39: $963-$ 967.

8. Cattaneo M, Moccetti M, Pasotti E, Faletra F, Porretta AP, Kobza R, et al. Three recurrent episodes of apical-ballooning Takotsubo cardiomyopathy in a man. Circulation 2015; 132: e377-e379, doi:10. 1161/CIRCULATIONAHA.115.017630.

9. Elesber AA, Prasad A, Lennon RJ, Wright RS, Lerman A, Rihal CS. Four-year recurrence rate and prognosis of the apical ballooning syndrome. J Am Coll Cardiol 2007; 50: 448-452.

10. Gianni M, Dentali F, Grandi AM, Sumner G, Hiralal R, Lonn E. Apical ballooning syndrome or takotsubo cardiomypathy: A systematic review. Eur Heart J 2006; 27: 1523-1529.

11. Sharkey SW. Takotsubo cardiomyopathy: Natural history. Heart Fail Clin 2013; 9: 123 -136.

12. Kurisu S. Prevalence of incidental coronary artery disease in takotsubo cardiomyopathy. Coron Artery Dis 2009; 20: 214-218.

13. Ito K, Sugihara H, Kawasaki T, Yuba T, Doue T, Tanabe T, et al. Assessment of ampulla (Takotsubo) cardiomyopathy with coronary angiography, two dimensional echocardiography and $99 \mathrm{mTc}$-tetrofosmin myocardial single photon emission computed tomography. Ann Nucl Med 2001; 15: 351-355.

14. Bybee KA, Prasad A, Barsness GW, Lerman A, Jaffe AS, Murphy JG, et al. Clinical characteristics and thrombolysis in myocardial infarction frame counts in women with transient left ventricular apical ballooning syndrome. Am J Cardiol 2004; 94: 343-346.

15. Kurisu S, Inoue I, Kawagoe T, Ishihara M, Shimatani Y, Nishioka $\mathrm{K}$, et al. Myocardial perfusion and fatty acid metabolism in patients with tako-tsubo-like left ventricular dysfunction. J Am Coll Cardiol 2003; 41: 743-748.

16. Fazio G, Sarullo FM, Novo G, Evola S, Lunetta M, Barbaro G, et al. Takotsubo cardiomyopathy and microcirculation. J Clin Monit Comput 2010; 24: 101-105.

17. Khalid N, Iqbal I, Coram R, Raza T, Fahsah I, Ikram S. Thrombolysis in myocardial infarction frame count in Takotsubo cardiomyopathy. Int J Cardiol 2015; 191: 107-108.

18. Sharkey SW, Lesser JR, Menon M, Parpart M, Maron MS, Maron BJ. Spectrum and significance of electrocardiographic patterns, troponin levels, and thrombolysis in myocardial infarction frame count in patients with stress (tako-tsubo) cardiomyopathy and comparison to those in patients with ST-elevation anterior wall myocardial infarction. Am J Cardiol 2008; 101: 1723-1728.

19. Elesber A, Lerman A, Bybee KA, Murphy JG, Barsness G, Singh M, et al. Myocardial perfusion in apical ballooning syndrome correlate of myocardial injury. Am Heart J 2006; 152: 469.e9-469.e13, doi:10.1016/j.ahj.2006.06.007

20. Kume T, Akasaka T, Kawamoto T, Yoshitani H, Watanabe N, Neishi $\mathrm{Y}$, et al. Assessment of coronary microcirculation in patients with takotsubo-like left ventricular dysfunction. Circ J 2005; 69: 934939.

21. Abe Y, Kondo M, Matsuoka R, Araki M, Dohyama K, Tanio H. Assessment of clinical features in transient left ventricular apical ballooning. J Am Coll Cardiol 2003; 41: 737-742.

22. Abdelmoneim SS, Mankad SV, Bernier M, Dhoble A, Hagen ME, Ness SA, et al. Microvascular function in Takotsubo cardiomyopathy with contrast echocardiography: Prospective evaluation and review of literature. J Am Soc Echocardiogr 2009; 22: 1249-1255.

23. Rigo F, Sicari R, Citro R, Ossena G, Buja P, Picano E. Diffuse, marked, reversible impairment in coronary microcirculation in stress cardiomyopathy: A Doppler transthoracic echo study. Ann Med 2009; 2: $1-9$.

24. Galiuto L, De Caterina AR, Porfidia A, Paraggio L, Barchetta S, Locorotondo G, et al. Reversible coronary microvascular dysfunction: A common pathogenetic mechanism in apical ballooning or
Tako-Tsubo syndrome. Eur Heart J 2010; 31: 1319-1327.

25. Meimoun P, Malaquin D, Benali T, Tribouilloy C. Assessment of coronary flow reserve by transthoracic Doppler echocardiography in left apical ballooning syndrome. Eur J Echocardiogr 2008; 9: 78 79.

26. Meimoun P, Malaquin D, Benali T, Boulanger J, Zemir H, Tribouilloy C. Transient impairment of coronary flow reserve in takotsubo cardiomyopathy is related to left ventricular systolic parameters. Eur J Echocardiogr 2009; 10: 265-270.

27. Sganzerla P, Alioto G, Funaro A, Passaretti B, Borghini E, Guglielmetto S. Transthoracic Doppler ultrasound coronary flow reserve evaluation: Preliminary insights into pathophysiology of Takotsubo cardiomyopathy. J Cardiovasc Med (Hagerstown) 2008; 9: $1229-1234$.

28. Nishikawa S, Ito K, Adachi Y, Katoh S, Azuma A, Matsubara H. Ampulla ('takotsubo') cardiomyopathy of both ventricles: Evaluation of microcirculation disturbance using ${ }^{99 \mathrm{~m}} \mathrm{Tc}$-tetrofosmin myocardial single photon emission computed tomography and Doppler guide wire. Circ J 2004; 68: 1076-1080.

29. Ito K, Sugihara H, Katoh S, Azuma A, Nakagawa M. Assessment of Takotsubo (ampulla) cardiomyopathy using ${ }^{99 \mathrm{~m} T \mathrm{~T}-\text { tetrofosmin myo- }}$ cardial SPECT: Comparison with acute coronary syndrome. Ann Nucl Med 2003; 17: 115-122.

30. Cimarelli S, Sauer F, Morel O, Ohlmann P, Constantinesco A, Imperiale A. Transient left ventricular dysfunction syndrome: Pathophysiological bases through nuclear medicine imaging. Int $J$ Cardiol 2010; 144: 212-218.

31. Hadase M, Kawasaki T, Asada S, Kamitani T, Kawasaki S, Sugihara H. Reverse redistribution of Tc- $99 \mathrm{~m}$ tetrofosmin in a patient with 'takotsubo' cardiomyopathy. Clin Nucl Med 2003; 28: 757-759.

32. Sato A, Aonuma K, Nozato T, Sekiguchi Y, Okazaki O, Kubota K, et al. Stunned myocardium in transient left ventricular apical ballooning: A serial study of dual I-123 BMIPP and Tl-201 SPECT. $J$ Nucl Cardiol 2008; 15: 671-679.

33. Tsuchihashi K, Ueshima K, Uchida T, Ohmura N, Kimura K, Owa $\mathrm{M}$, et al. Transient left ventricular apical ballooning without coronary artery stenosis: A novel heart syndrome mimicking acute myocardial infarction. J Am Coll Cardiol 2001; 38: 11-18.

34. Matsuo S, Nakajima K, Kinuya S, Yamagishi M. Diagnostic utility of 123I-BMIPP imaging in patients with Takotsubo cardiomyopathy. J Cardiol 2014; 64: 49-56.

35. Bybee KA, Murphy J, Prasad A, Wright RS, Lerman A, Rihal CS, et al. Acute impairment of regional myocardial glucose uptake in the apical ballooning (takotsubo) syndrome. J Nucl Cardiol 2006; 13: 244-250.

36. Yoshida T, Hibino T, Kako N, Murai S, Oguri M, Kato K, et al. A pathophysiologic study of tako-tsubo cardiomyopathy with F-18 fluorodeoxyglucose positron emission tomography. Eur Heart $J$ 2007; 28: $2598-2604$.

37. Christensen TE, Bang LE, Holmvang L, Ghotbi AA, Lassen ML, Andersen F, et al. Cardiac ${ }^{99} \mathrm{~m} T c$ sestamibi SPECT and ${ }^{18 F}$ FDG PET as viability markers in Takotsubo cardiomyopathy. Int J Cardiovasc Imaging 2014; 30: 1407-1416.

38. Feola M, Chauvie S, Rosso GL, Biggi A, Ribichini F, Bobbio M, et al. Reversible impairment of coronary flow reserve in takotsubo cardiomyopathy: A myocardial PET study. J Nucl Cardiol 2008; 15: $811-817$.

39. Owa M, Aizawa K, Urasawa N, Ichinose H, Yamamoto K, Karasawa $\mathrm{K}$, et al. Emotional stress-induced 'Ampulla Cardiomyopathy' discrepancy between the metabolic and sympathetic innervation imaging performed during the recovery course. Jpn Circ J 2001; 65: 349-352.

40. Eitel I, von Knobelsdorff-Brenkenhoff F, Bernhardt P, Carbone I, Muellerleile K, Aldrovandi A, et al. Clinical characteristics and cardiovascular magnetic resonance findings in stress (takotsubo) cardiomyopathy. JAMA 2011; 306: 277-286.

41. Wittstein IS, Thiemann DR, Lima JAC, Baumghman KL, Schulman SP, Gerestenblith G, et al. Neurohormonal features of myocardial stunning due to sudden emotional stress. $N$ Engl J Med 2005; 352: $539-548$.

42. Mann DL, Kent RL, Parsons B, Cooper G. Adrenergic effects on the biology of the adult mammalian cardiocyte. Circulation 1992; 85: 790-804.

43. Singal PK, Kapur N, Dhillon KS, Beamish RE, Dhalla NS. Role of free radicals in catecholamine-induced cardiomyopathy. Can $J$ Physiol Pharmacol 1982; 60: 1390-1397.

44. Abraham J, Mudd JO, Kapur NK, Klien K, Champion HC, Wittstein IS. Stress cardiomyopathy after intravenous administration of catecholamines and beta-receptor agonists. J Am Coll Cardiol 2009; 53: $1320-1325$. 
45. Uchida Y, Egami H, Uchida Y, Sakurai T, Kanai M, Shirai S, et al. Possible participation of endothelial cell apoptosis of coronary microvessels in the genesis of Takotsubo cardiomyopathy. Clin Cardiol 2010; 33: 371-377.

46. Lacy CR, Contracta RJ, Robbins ML, Tannenbaum AK, Moreyra $\mathrm{AE}$, Chelton S, et al. Coronary vasoconstriction induced by mental stress (simulated public speaking). Am J Cardiol 1995; 75: 503-505.

47. Chilian WM. Adrenergic vasomotion in the coronary microcirculation. Basic Res Cardiol 1990; 85: 111-120.

48. Kawano H, Okada R, Yano K. Histological study on the distribution of autonomic nerves in the human heart. Heart Vessels 2003; 18: $32-39$.

49. Pierpont GL, DeMaster EG, Cohn JN. Regional differences in adrenergic function within the left ventricle. Am J Physiol 1984; 246: H824-H849.

50. Paur H, Wright PT, Sikkel MB, Tranter MH, Mansfield C, O'Gara $\mathrm{P}$, et al. High levels of circulating epinephrine trigger apical cardiodepression in a beta2-adrenergic receptor/Gi-dependent manner: A new model of Takotsubo cardiomyopathy. Circulation 2012; 126: 697-706.

51. Spinelli L, Trimarco V, Di Marino S, Iaccarino G, Trimarco B. L41Q polymorphism of the $\mathrm{G}$ protein coupled receptor kinase 5 is associated with left ventricular apical ballooning syndrome. Eur J Heart Fail 2010; 12: 13-16.

52. Akashi YJ, Nakazawa K, Sakakibara M, Miyake F, Musha H, Sasaka K. ${ }^{123}$ I-MIBG myocardial scintigraphy in patients with "takotsubo" cardiomyopathy. J Nucl Med 2004; 45: 1121-1127.

53. Nef HM, Möllmann H, Akashi YJ, Hamm CW. Mechanisms of stress (Takotsubo) cardiomyopathy. Nat Rev Cardiol 2010; 7: 187193.

54. Y-Hassan S. Acute cardiac sympathetic disruption in the pathogenesis of the takotsubo syndrome: A systematic review of the literature to date. Cardiovasc Revasc Med 2014; 159: 35-42.

55. Cannon WB. "Voodoo" death. Am Anthropologist 1942; 44: 169-118. / Cited by: Engel G. Sudden and rapid death during psychological stress. Ann Intern Med 1971; 74: 771-782.

56. Cheung RT, Hachinski V. The insula and cerebrogenic sudden death. Arch Neurol 2000; 57: 1685-1688.

57. Raab W, Stark E, Macmillan WH, Gigee WR. Sympathogenic origin and antiadrenergic prevention of stress-induced myocardial lesions. Am J Cardiol 1961; 8: 203-211.
58. Lyon AR, Rees PS, Prasad S, Poole-Wilson PA, Harding SE. Stress (Takotsubo) cardiomyopathy: A novel pathophysiological hypothesis to explain catecholamine-induced acute myocardial stunning. Nat Clin Pract Cardiovasc Med 2008; 5: 22-29.

59. Mendelsohn ME, Karas RH. The protective effects of estrogen on the cardiovascular system. N Engl J Med 1999; 340: 1801-1811.

60. Vitale C, Mendelsohn ME, Rosano GM. Gender differences in the cardiovascular effect of sex hormones. Nat Rev Cardiol 2009; 6: $532-542$.

61. Taddei S, Virdis A, Ghiadoni L, Mattei P, Sudano I, Bernini G, et al. Menopause is associated with endothelial dysfunction in women. Hypertension 1996; 28: 576-582.

62. Kaski JC, Cox ID, Crook JR, Salomone OA, Fredericks S, Hann C, et al. Differential plasma endothelin levels in subgroups of patients with angina and angiographically normal coronary arteries: Coronary Artery Disease Research Group. Am Heart J 1998; 136: $412-417$.

63. Stöllberger C, Finsterer J. Why does Takotsubo ("broken heart syndrome") affect more females than males? Int J Cardiol 2011; 147: $175-176$.

64. Martin EA, Prasad A, Rihal CS, Lerman LO, Lerman A. Endothelial function and vascular response to mental stress are impaired in patients with apical ballooning syndrome. J Am Coll Cardiol 2010; 56: $1840-1846$.

65. Barletta G, Del Pace S, Boddi M, Del Bene R, Salvadori C, Bellandi $\mathrm{B}$, et al. Abnormal coronary reserve and left ventricular wall motion during cold pressor test in patients with previous left ventricular ballooning syndrome. Eur Heart J 2009; 30: 3007-3014.

66. Ueyama T, Kasamatsu K, Hano T, Tsuruo Y, Ishikura F. Catecholamines and estrogen are involved in the pathogenesis of emotional stress-induced acute heart attack. Ann NY Acad Sci 2008; 1148: $479-485$.

67. Ueyama T, Ishikura F, Matsuda A, Asanuma T, Ueda K, Ichinose M, et al. Chronic estrogen supplementation following ovariectomy improves the emotional stress-induced cardiovascular responses by indirect action on the nervous system and by direct action on the heart. Circ J 2007; 71: 565-573.

68. Brenner R, Weilenmann D, Maeder MT, Jörg L, Bluzaite I, Rickli $\mathrm{H}$, et al. Clinical characteristics, sex hormones, and long-term follow-up in Swiss postmenopausal women presenting with Takotsubo cardiomyopathy. Clin Cardiol 2012; 35: 340-347. 